Y.J. Kao PhD MD, ${ }^{*}$ Tan Mian MB ChB, $\dagger$ Sam Kleinman MD, Gabor B. Racz MB ChB

\section{Hyperkalaemia: a complication of warm heart surgery}

Intraoperative variation of the plasma potassium concentration poses a challenge to the knowledge and skill of the anaesthetist. ' Recently, warm heart surgery, which uses warm blood cardioplegia to arrest the heart followed by continuous warm blood perfusion of coronary arteries to maximize myocardial preservation, has become popular. $^{2-5}$ The interaction between several elements of this technique (e.g., normothermia and repeated doses of cardioplegia), and anaesthesia has not been addressed. In this current communication, we present a case of severe hyperkalaemia $\left([\mathrm{K}]=13.6 \mathrm{meq} \cdot \mathrm{L}^{-1}\right)$, which resulted from using excess warm blood cardioplegia for myocardial preservation.

On présente un cas d'hyperkaliémie $\left(13,6 \mathrm{mmol} \cdot \mathrm{L}^{-1}\right)$ survenant au cours d'une circulation extracorporelle sous cardioplégie sanguine chaude $\left(\mathrm{K}^{+} 40-60 \mathrm{mmol} \cdot \mathrm{L}^{-1}\right)$. On a initié un traitement à l'épinéphrine, au chlorure de calcium, au bicarbonate de sodium et au furosémide. La performance myodardique est augmentée par de l'amrinone et le rythme cardiaque contrôlé par entrainement segmentaire $A-V$. On émet l'opinion que l'hyperkaliémie fut déclenchée par l'association du type dintervention (remplacement mitral) à la cardioplégie chaude. L'objectif de cette observation est de mettre en garde contre la possibilité d'hyperkaliémie associée à la cardioplégie chaude et de proposer une thérapeutique curative.

\section{Key words}

ANAESTHESIA: cardiac;

COMPLICATIONS: hyperkalaemia;

IONS: potassium;

SURGERY: cardiopulmonary bypass.

From the Department of Anesthesiology, Texas Tech

University Health Sciences Center, Lubbock, Texas 79430.

Address Correspondence to: Dr. Y.J. Kao,

*Current address: Department of Anesthesiology, University of California Irvine Medical Center, 101 City Drive South,

Orange, California 92668, Bldg. 53, Rt. 81 A.

†Current address: 37 St. Agnes Road, Heath Cardiff, CF4 4AN, UK.

Accepted for publication 17th September, 1992.

\section{Case report}

A 56-yr-old woman, ASA physical status class IV, was admitted for tricuspid and mitral valve replacement. Past medical history included rheumatic fever at the age of ten. Ten years before the current admission, severe tricuspid valve stenosis and regurgitation as well as mixed mitral valve disease were diagnosed. Surgical intervention was recommended but refused by the patient at that time. Her presenting complaints included fatigue, dyspnoea and lethargy. Physical examination revealed a thin, cachectic lady in severe distress with tachypnoea, ascites, pedal oedema and pulmonary oedema. Her maintenance medication includes spironolactone $50 \mathrm{mg}$ and furosemide 40 $\mathrm{mg}$ twice daily, warfarin $2.5 \mathrm{mg}$, digoxin $0.125 \mathrm{mg}$ and atenolol $50 \mathrm{mg}$ once daily. Vital signs were: weight 58 $\mathrm{kg}$, blood pressure $100 / 65 \mathrm{mmHg}$, and heart rate 110 $\mathrm{min}^{-1}$. Blood cell counts and electrolyte concentrations were within normal limits except that blood urea nitrogen was $36 \mathrm{mg} \cdot \mathrm{dl}^{-1}$ and creatinine $1.2 \mathrm{mg} \cdot \mathrm{dl}^{-1}$. Arterial blood gas analysis while breathing room air showed $\mathrm{pH}$ 7.42, $\mathrm{PaO}_{2} 66 \mathrm{mmHg}$ and $\mathrm{PaCO}_{2} 32 \mathrm{mmHg}$. Echocardiographic studies of tricuspid valve revealed mild tricuspid stenosis and severe regurgitation. Severe mitral regurgitation and bilateral atrial enlargement were also noted.

Preoperative medication included morphine sulfate 5 $\mathrm{mg}$ and scopolamine $0.4 \mathrm{mg}$ one hour before induction of anaesthesia with sufentanil $150 \mu \mathrm{g}$ and midazolam $0.5 \mathrm{mg}$. Muscle relaxation was achieved with pipecuronium $5 \mathrm{mg}$. After orotracheal intubation, intermittent 
positive pressure ventilation was initiated and minute ventilation was adjusted to maintain an end tidal $\mathrm{PCO}_{2}$ of $30 \mathrm{mmHg}$. Anaesthesia was maintained with additional sufentanil $250 \mu \mathrm{g}$ and midazolam $5 \mathrm{mg}$ in divided doses before surgical incision. A right subclavian venous cannula and a left radial arterial cannula were inserted for haemodynamic monitoring. Because the tricuspid valve was to be replaced, the surgeon requested that a pulmonary artery catheter not be placed. Other monitors included urinary bladder thermometer, oesophageal thermometer, noninvasive blood pressure (Dinamap), pulse oximeter and capnometer. Cardiopulmonary bypass at $33^{\circ}$ was instituted via the vena cava to the ascending aorta. The perfusion pressure was maintained between 50 and $80 \mathrm{mmHg}$ by infusion of phenylephrine and nitroglycerin. After crossclamping the ascending aorta, warm blood cardioplegia $\left(37^{\circ}\right)$ containing a high concentration of potassium $\left([\mathrm{K}]-20\right.$ to $\left.30 \mathrm{meq} \cdot \mathrm{L}^{-1}\right)$ was infused through a cannula at the aortic root. Asystole occurred after the infusion of $500 \mathrm{ml}$ of the cardioplegia. Following asystole, the cardioplegic solution was changed to low potassium $\left([\mathrm{K}]=6-8 \mathrm{meq} \cdot \mathrm{L}^{-1}\right)$ blood cardioplegia $\left(37^{\circ}\right)$ continuous infusion for myocardial preservation. The mitral valve was approached through a right atriotomy and septostomy. Myocardial electromechanical activity returned during replacement of the mitral valve. It was decided to resume high potassium blood cardioplegia infusion which also failed to arrest the heart. In an attempt to stop the electromechanical activity, the potassium concentration in the blood cardioplegia was further increased (estimated concentration 40 to 60 $\mathrm{meq} \cdot \mathrm{L}^{-1}$ ). The myocardium was finally arrested after a total dose of potassium chloride of 90 meq. Mitral valve replacement was then completed, septostomy repaired and the tricuspid valve was replaced with a porcine valve (Edward-Carpentier valve). The rest of the operation was uneventful. Aortic crossclamp time was $90 \mathrm{~min}$.

After the valve replacements, the atriotomy was closed, and the aortic crossclamp was removed after air was vented from the left ventricle and aorta. Perfusion of the coronary arteries was reestablished. However, despite 30 min of continuous circulatory support, asystole persisted. The body core temperature (urinary bladder) was $36.1^{\circ}$ C. Arterial blood gas and serum electrolytes were $\mathrm{pH}$ 7.4, $\mathrm{PaO}_{2} 450 \mathrm{mmHg}$ and $\mathrm{PaCO}_{2} 41 \mathrm{mmHg}$, [Na] $=$ $136 \mathrm{meq} \cdot \mathrm{L}^{-1} ;[\mathrm{K}]=13.6 \mathrm{meq} \cdot \mathrm{L}^{-1} ;[\mathrm{Ca}]=1.2$ $\mathrm{meq} \cdot \mathrm{L}^{-1}$. Repeat serum electrolytes were $[\mathrm{Na}]=134$ $\mathrm{meq} \cdot \mathrm{L}^{-1} ;[\mathrm{K}]=13.1 \mathrm{meq} \cdot \mathrm{L}^{-1}$ and $[\mathrm{Ca}]=1.1$ $\mathrm{meq} \cdot \mathrm{L}^{-1}$. Atrial and ventricular pacing wires were placed and A-V sequential pacing started. The ventricular capturing threshold was initially found to be high and a wide sinuous QRS wave complex was seen on the ECG. On visual inspection, contractility of the myocardium was judged to be grossly inadequate. Treatment of hyperkalaemia was therefore started before attempts to wean the patient from cardiopulmonary bypass. Therapy for the hyperkalaemia included the infusion of epinephrine at $0.05 \mu \mathrm{g} \cdot \mathrm{kg}^{-1} \cdot \mathrm{min}^{-1}$ and sodium bicarbonate $50 \mathrm{meq}$. Calcium chloride $1 \mathrm{~g}$ bolus and furosemide $10 \mathrm{mg}$ were also given. The perfusionist was instructed to increase fresh gas flow to reduce blood $\mathrm{CO}_{2}$ level. Amrinone, 5 $\mu \mathrm{g} \cdot \mathrm{kg}^{-1} \cdot \mathrm{min}^{-1}$ was also infused to improve the myocardium contractility. Thirty minutes after the initiation of hyperkalaemia therapy, the QRS wave narrowed, myocardial contractility improved and repeated plasma potassium concentration was found to be $6.5 \mathrm{meq} \cdot \mathrm{L}^{-1}$. The patient was then weaned from cardiopulmonary bypass with blood pressure of $90 / 50 \mathrm{mmHg}$. Total cardiopulmonary bypass time was $160 \mathrm{~min}$ and during cardiopulmonary bypass, the urine output was $250 \mathrm{ml}$. Ventricular preload was maintained with packed red blood cells and 5\% albumin solution. Blood coagulation abnormalities were corrected with protamine and fresh frozen plasma. Cardiac contractility was supported with infusions of amrinone and epinephrine. Cardiac rhythm was controlled with $\mathrm{A}-\mathrm{V}$ sequential pacing at a rate of $90 \mathrm{~min}^{-1}$ to counter sinus bradycardia and first degree A-V block. A mild alkalaemia ( $\mathrm{pH} 7.5$ ) was induced by hyperventilation. The loss of pacemaker capturing was treated with small boluses $(250 \mathrm{mg}$ ) of calcium chloride. Serum electrolyte levels were monitored every $30 \mathrm{~min}$ to quantitate potassium and calcium levels. After skin closure, the patient was transferred to the post-surgical cardiac care unit with ventilatory support.

Over the next two hours, a brisk diuresis ensued (1800 $\mathrm{ml}$ ). The serum potassium concentration further decreased to $4.5 \mathrm{meq} \cdot \mathrm{L}^{-1}$. The trachea was extubated 12 hrs after the operation. At postoperative day one, plasma creatinine concentration was $1.3 \mathrm{mg} \cdot \mathrm{dl}^{-1}$ and blood urea nitrogen concentration was $33 \mathrm{mg} \cdot \mathrm{dl}^{-1}$. The remainder of her recovery was uneventful.

\section{Discussion}

We present a case of extreme hyperkalaemia (potassium level of $13.6 \mathrm{meq} \cdot \mathrm{L}^{-1}$ ) at the end of cardiopulmonary bypass after warm heart surgery for mitral valve and tricuspid valve replacement. While electrolyte disturbance is a common clinical observation after cardiopulmonary bypass, the degree of plasma potassium concentration elevation in our patient is rare. We believe that the nature of the surgical procedure (mitral replacement), the technique of the myocardial preservation (warm heart surgery) and, possibly, renal insufficiency are all contributing factors to the hyperkalaemia.

Hyperkalaemic cardiac arrest, induced by perfusion of a high potassium solution (cardioplegia) via the coronary 
arteries after crossclamping of the aorta, has been used extensively over the last $20 \mathrm{yrs}$ in cardiovascular surgery. ${ }^{6,7}$ Myocardial standstill provides a motionless surgical field and reduces the metabolic demand of the myocardium and, therefore, prolongs the allowable operation time. Additional myocardial protection is usually provided by hypothermia. ${ }^{8,9}$

The major disadvantages of hypothermic diastolic cardiac arrest include: (1) myocardial high energy compounds consumption and inadequate energy production secondary to the effect of low temperature on the enzymes of glycolysis pathway; (2) reperfusion injury, a complex phenomenon that is still poorly understood; and (3) disturbance to the myocardial membranous structures caused by the rapid change of the temperature. ${ }^{2,10}$

Over the last decade, through laboratory animal investigations, a new myocardial preservation technique involving continuous perfusion of the myocardium with warmed blood and supplemental potassium has been developed. ${ }^{2,5}$ The energy-generating mechanism of the myocardium is maintained, and all of the shortcomings of the above-mentioned cold crystalloid cardioplegia are ameliorated. The utilization of blood cardioplegia and the continuous infusion of the heart with warm $\left(37^{\circ}\right)$ potassium ion supplemented blood during aortic crossclamping are the two functional elements of so-called "warm heart" surgery. ${ }^{2}$

Controlled perfusion of the myocardium by infusion of cardioplegia at the aortic root requires a competent aortic valve. Indeed, when aortic valvular regurgitation is suspected, the retrograde infusion of cardioplegia through the coronary sinus to arrest the heart is often used. ${ }^{11-13}$ A physiologically intact aortic valve can become functionally incompetent following surgical manipulation. Retrocardiac padding for surgical exposure, traction of the mitral annulus during mitral valve replacement and the proximate position of right atrial cannulae to the noncoronary sinus have all been implicated in causing an incompetent aortic valve. ${ }^{10}$ When the aortic valve becomes incompetent during a surgical procedure, repeat cardioplegia administration becomes ineffective. A high concentration of potassium containing fluid flows first into the left ventricle, then through the sump tube, and returns to the cardiopulmonary pump reservoir. Unrestrained cardioplegia usage may result in hyperkalaemia.

With hypothermic techniques, when cellular activity of the myocardium is suppressed by low temperature, the return of myocardial electromechanical activity and the need for repeat cardioplegia infusion is infrequent. However, when the warm heart surgery technique is used, spontaneous myocardial electrical and mechanical activities can return more frequently at physiological temperature. ${ }^{2}$ The surgical field may become less than ideal,
TABLE Management of hyperkalaemia

Reduction of plasma potassium concentration

1 Facilitate intracellular distribution of potassium ion

- Beta ${ }_{2}$ adrenergic stimulation

- Alkalaemia, respiratory or metabolic

- Glucose-insulin infusion

2 Excretion of potassium

- Loop diuretics

- Na-K exchange resin enema (keyexalate)

- Haemofiltration

Antagonism of hyperkalaemia

1 Increase plasma calcium concentration

2 A-V sequential pacing of the heart

and more importantly, the myocardial energy demand may overwhelm supply. In order to prevent the irreversible ischaemic contracture, "stone heart," as a result of myocardial ischaemia at normothermia, ${ }^{14}$ repeat cardioplegia infusion to preserve myocardium is clearly indicated. However, overzealous treatment of myocardial electrical and mechanical activity by hyperkalaemic cardioplegia when the competency of the aortic valve is jeopardized by surgical manipulation will lead to total body hyperkalaemia as experiened in our patient.

The role of renal insufficiency in hyperkalaemia should not be overlooked. Preoperatively, the patient had an increased blood urea nitrogen level - a strong indication of renal insufficiency. The patient was also taking a potassium sparing agent. The decreased capacity of the kidneys to handle the potassium load during cardiopulmonary bypass would accentuate the post-bypass plasma potassium level.

The treatment of hyperkalaemia (Table) consists of two goals: namely the reduction of the plasma potassium level and the antagonism of the effect of hyperkalaemia. The plasma potassium concentration can be reduced by either translocation of the potassium ion into the intracellular space which can be accomplished by alkalemia, Beta ad renergic stimulation as well as insulin-glucose infusion, or elmination from the body by a loop diuretic agent as well as Na-K exchange resin enema. ${ }^{1,15}$ When the patient is still being supported with cardiopulmonary bypass, haemofiltration may also be used. The antagonism of hyperkalaemic effects can be achieved with intravenous infusion of calcium. ${ }^{1}$ An A-V sequential pacemaker must be used to maintain cardiac rhythm when asystole is present. ${ }^{16}$ The treatment of hyperkalaemia diagnosed immediately after cardiopulmonary bypass for warm heart surgery, on the other hand, must be modified in light of the peculiar physiological and pharmacological considerations associated with warm heart surgery. The adequacy of cerebral protection at physiological temper- 
ature has been a major concern regarding the safety of warm heart surgery. ${ }^{2}$ Also, the effect of haemodynamic instability on cerebral perfusion during the post cardiopulmonary bypass period must also be resolved. Similarly, the potential development of "stone heart" at normothermia after incomplete myocardial preservation should be recognized. ${ }^{14}$ These factors impose certain restrictions on the method of treating hyperkalaemia. Haemofiltration after cardiopulmonary bypass may be undesirable because an arterial venous shunt may impose an additional burden on the recovering myocardium. However, initiation of haemofiltration prior to the weaning of the patient from cardiopulmonary bypass can be beneficial.

The management of this patient when hyperkalaemia was first recognized during cardiopulmonary bypass until the achievement of normokalaemia in the intensive care unit is summarized. Throughout the hyperkalaemic period, an $\mathrm{A}-\mathrm{V}$ sequential pacemaker was used to maintain a stable cardiac rhythm. Sodium bicarbonate and hyperventilation were used to achieve alkalosis. Epinephrine infusion to provide beta adrenergic stimulation was also given, both for beta ${ }_{1}$ adrenergic inotropic and chronotropic support and to provide a beta ${ }_{2}$ adrenergic hypokalaemic effect. Other catecholamine inotropic agents such as dopamine or dobutamine were not used because they may not provide a beta ${ }_{2}$ adrenergic hypokalaemic effect. Since the kidneys have not been subjected to temperature fluctuations during cardiopulmonary bypass after warm heart surgery, renal excretion of potassium is maintained. Amrinone ws infused to provide additional inotropic activity and to counter the dose-limiting vasoconstrictive activity of epinephrine. Additionally, furosemide was also given to promote diuresis which facilitates the excretion of total body potassium load. Before the eventual normalization of the potassium level in the plasma, repeated boluses of calcium chloride were administered to counteract the effect of hyperkalaemia. While glucose-insulin infusion has been used extensively in routine clinical medicine to treat hyperkalaemia, in light of the controversy surrounding the deleterious effect of hyperglacaemia on cerebral ischaemia, especially when hypothermia protection is not present during warm heart surgery, we elected not to administer this form of therapy.

\section{Acknowledgements}

The authors with to express their gratitude to Miss Cameo J. Rogers and Ms. Julie A. Schlesinger for their expert secretarial assistance.

\section{References}

1 Stoelting $R K$, Dierdorf SF, McCammon RL. Water and electrolyte disturbances. In: Stoelting RK, Diendorf SF,
McCammon RL (Eds.). Anesthesia and Coexisting Disease, New York: Churchill Livingston Inc., 1988; 445-72.

2 Lichtenstein SV, Ashe KA, el Dalati H, Cusiamo RJ, Panos A, Slutsky AS. Warm heart surgery. J Thorac Cardiovasc Surg 1991; 101: 269-74.

3 Fremes SE, Christakis GT, Weisel RD, et al. A clinical trial of blood and crystalloid cardioplegia. $J$ Thorac Cardiovasc Surg 1984; 88: 726-41.

4 Buckberg GD. Oxygenated cardioplegia: blood is a many splendored thing. Ann Thorac Surg 1990; 50: 175-7.

5 Teoh KH, Christakis GT, Weisel RD, et al. Accelerated myocardial metabolic recovery with terminal warm blood cardioplegia. J Thorac Cardiovasc Surg 1986; 91: 888-95.

6 Gay WA Jr. Potassium-induced cardioplegia. Ann Thorac Surg 1975; 20: 95-100.

7 Axford-Gatley RA, Wilson GJ, Feindel CM. Comparison of blood-based and asanguineous cardioplegic solutions administered at $4^{\circ} \mathrm{C}$. An ultrastructural morphometric study in the dog. J Thorac Cardiovasc Surg 1990; 100: 400-9.

8 Michaelis $L L$. Intraoperative protection of the myocardium. Ann Thorac Surg 1975; 20: 3-6.

9 Brody WR, Reitz BA. Topical hypothermic protection of the myocardium. Ann Thorac Surg 1975; 20: 66-71.

10 Buckberg $G D$. Myocardial protection during adult cardiac surgery. In: Baue AE, Geha AS, Hammond GL, Laks H, Naunheim KS (Eds). Glenn's Thoracic and Cardiovascular Surgery, 5th ed., East Norwalk, CT: Appleton and Lange, 1991; 1417-41.

11 Yonenaga $K$, Yasui $H$, Kado $H$, et al. Myocardial protection by retrograde cardioplegia in arterial switch operation. Ann Thorac Surg 1990; 50: 238-42.

12 Sutter FP, Goldman SM, Clancy M, et al. Continuous retrograde blood cardioplegia. Ann Thorac Surg 1991; 51: 136-7.

13 Menasche P, Subayi J, Piwnica A. Retrograde coronary sinus candioplegia for aortic valve operations: a clinical report on 500 patients. Ann Thorac Surg 1990; 49: 556-63.

14 Cooley DA, Reul GJ, Wukasch DC. Ischemic contracture of the heart: "stone heart." Amer J Cardiol 1972; 29: 575-7.

15 Blumberg $A$, Weidman $P$, Shaw $S$, Gradinger $M$. Effect of various therapeutic approaches on plasma potassium and major regulating factors in terminal renal failure. Amer J Med 1988; 85: 507-12.

16 Escher DW. The use of cardiac pacemakers. In: Braunwald E (Ed.) Heart Disease: A Textbook of Cardiovascular Medicine, Philadelphia: WB Saunders, 1980; 744-72. 